\title{
Characteristics of a series-connected two-evaporator refrigerating system
}

\author{
Chao-Jen Li, Chin-Chia Su * \\ Department of Mechanical Engineering, National Taiwan University, No. 1, Sec. 4, Roosevelt Rd., \\ Taipei 106, Taiwan, ROC
}

Received 24 March 2004; accepted 14 July 2004

Available online 25 September 2004

\begin{abstract}
Based on the Buckingham Pi theorem, this study derives the dimensionless correlations to characterize a series-connected two-evaporator refrigerating system with propane (R-290) as the refrigerant. Experimental data are substituted into the correlations to demonstrate the most relevant factors. Simplified correlations are then obtained.

The analytical results show that the mass flow rate of refrigerant $\left(\dot{m}_{\mathrm{r}}\right)$ is primarily affected by the condensing pressure, length of the high-temperature capillary tube, and the subcooling of refrigerant, while the heat transfer coefficients of refrigerant in the evaporators $\left(\mathrm{hc}_{\mathrm{H}}\right.$ and $\left.\mathrm{hc} \mathrm{c}_{\mathrm{L}}\right)$ are affected by the condensing pressure and the logarithmic-mean temperature difference of the specific evaporator. However, $\mathrm{hc}_{\mathrm{H}}$ and $\mathrm{hc}_{\mathrm{L}}$ are also affected by the lengths of the low- and high-temperature capillary tube, respectively. Additionally, the ratio of the cooling capacity of the high-temperature evaporator to the total capacity $(\alpha)$ is primarily affected by the condensing pressure and the logarithmic-mean temperature difference of both evaporators. The differences between the calculated and experimental data are between $-4 \%$ and $+5 \%,-16 \%$ and $+16 \%$, $-12 \%$ and $+16 \%$, and $-10 \%$ and $+10 \%$ for $\dot{m}_{\mathrm{r}}, \mathrm{hc}_{\mathrm{H}}, \mathrm{hc}_{\mathrm{L}}$, and $\alpha$, respectively.

(c) 2004 Elsevier Ltd. All rights reserved.
\end{abstract}

Keywords: Two-evaporator; R-290; Refrigerating system; Dimensionless correlation

\footnotetext{
${ }^{*}$ Corresponding author. Tel./fax: +88622368 7352.

E-mail address: chinchiasu@ntu.edu.tw (C.-C. Su).
} 


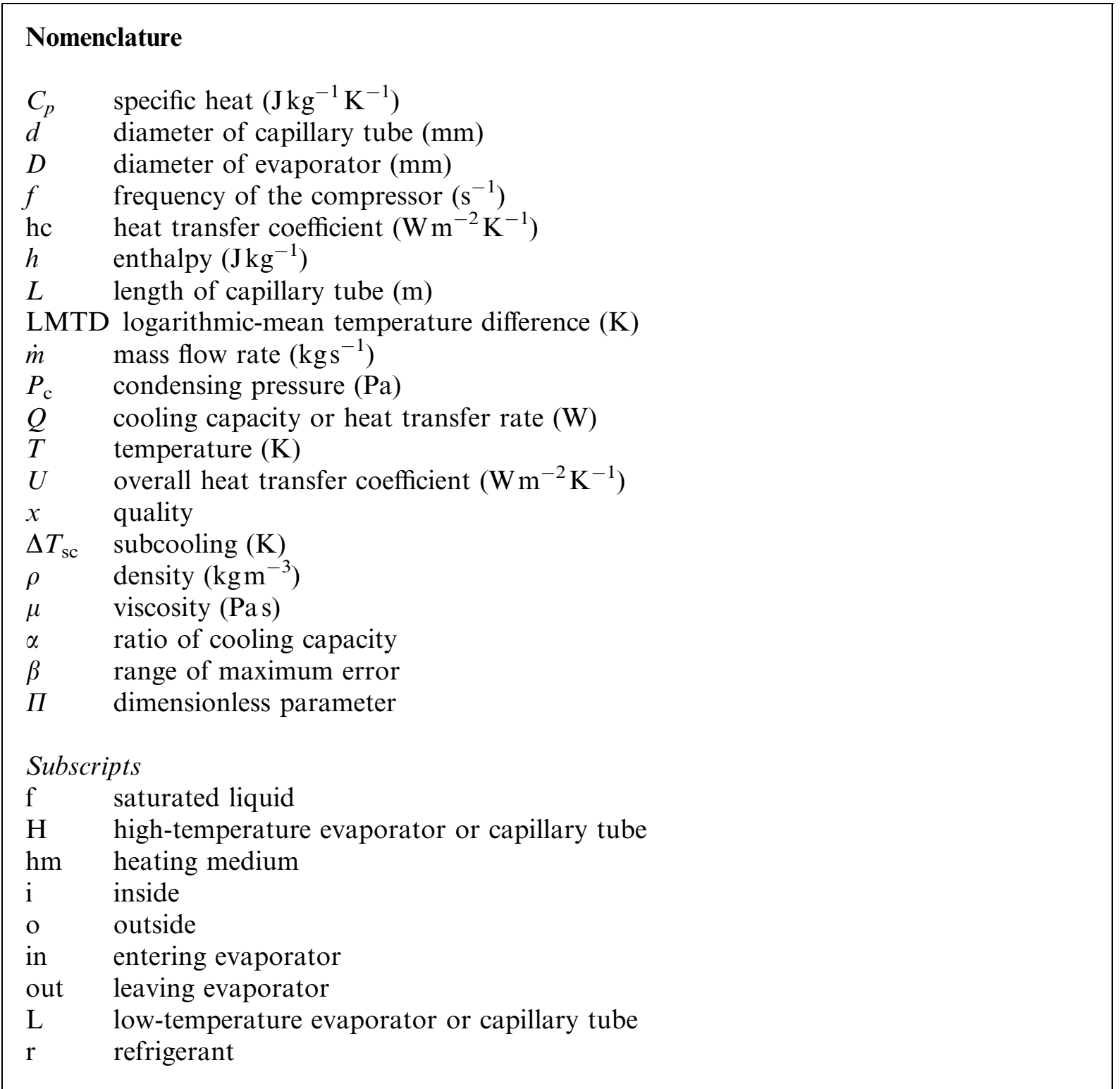

\section{Introduction}

From a thermodynamic viewpoint, a refrigerator with two evaporators in series and one capillary tube outperforms that with only one evaporator. Lorenz-Meutzner [1] proposed a twoevaporator refrigerator with zeotropic refrigerant R22/R 11 and experimentally demonstrated a power saving of up to $20 \%$ compared to a conventional refrigerator with R-12. Simmons et al. $[2,3]$ proposed that the modified Lorenz-Meutzner cycle has a power saving of $6.5 \%$ over that of the conventional refrigerator. However, the proposed models can only use zeotropic refriger- 
ant. With pure, azeotropic, or zeotropic refrigerants, different evaporating temperatures can be obtained by using the refrigerating system containing two capillary tubes and two evaporators connected in series [4].

The capillary tube reduces the pressure of the liquid refrigerant and regulates the flow rate of refrigerant to the evaporator. Li et al. [5], Kuehl-Goldschmidt [6], and Wijaya [7] presented detailed test data on the performance of a family of capillary tubes charged with R-12, R-22, and R-134a, respectively.

Both homogeneous and separated models simulating the mass flow rate of refrigerant through a capillary tube were developed to optimize the size of capillary tube [8-11]. However, the calculating processes involved were highly complex. Dimensionless analyses [12-14] thus were applied for simplifying the calculating processes.

The performance of the evaporator in a refrigerating system can be affected by the two-phase heat transfer coefficient of refrigerant [15-18]. For a system with two evaporators connected in series, the distribution of the cooling load between the evaporators may vary. Further studies therefore are needed.

CFC and HCFC refrigerants, such as R-12 and R-22, with a high ozone depleting potential (ODP) and global warming potential (GWP) have had their use restricted [19]. The zero ODP and extremely low GWP characteristics of certain hydrocarbons (HCs), e.g., propane (R-290), are extremely attractive in this aspect. The refrigerating properties of R-290 closely resemble those of R-22, thus making R-290 a proposing alternative to R-22. However, the flammability of R-290 in air should not be ignored.

This study develops the dimensionless correlations for the mass flow rate of refrigerant $\left(\dot{m}_{\mathrm{r}}\right)$, the heat transfer coefficients of refrigerant in the high- and low-temperature evaporators $\left(\mathrm{hc}_{\mathrm{H}}\right.$ and $h c_{L}$ ), and the ratio of the cooling capacity of the high-temperature evaporator to the total capacity $(\alpha)$ based on the experimental results and Buckingham Pi theorem. Furthermore, the experimental measurements of $\dot{m}_{\mathrm{r}}, \mathrm{hc}_{\mathrm{H}}$, and $\mathrm{hc}_{\mathrm{L}}$ are compared with the calculated results from the correlations in the literature [12,15-18]. Finally, the relative errors of the correlations are analyzed.

\section{Experimental apparatus}

Fig. 1 shows the experimental facility of a series-connected two-evaporator refrigerating system with R-290. The test apparatus comprises a refrigerant loop and two heat-exchange fluid loops. The refrigerant loop consists of a reciprocating compressor, a condenser, a filter-dryer, a refrigerant flow meter, a sight glass, an electromagnetic valve, two capillary tubes, two evaporators, and some valves. The states of the working fluids are monitored using T-type thermocouples and pressure gauges as illustrated in Fig. 1.

The frequency converter controls the reciprocating compressor, and the output of the converter for stable operation can be adjusted between 40 and $80 \mathrm{~Hz}$. The condenser is a finned-tube heat exchanger with a fan. The condensing pressure of the system is influenced by the rotating speed of the fan which is controlled via a voltage transformer.

The evaporators and capillary tubes are all made of copper and heat-insulated. Table 1 lists the dimensions of these components. The two evaporators are double-tube type and have the same dimensions. Notably, $D_{\mathrm{i}, \mathrm{i}}$ and $D_{\mathrm{i}, \mathrm{o}}$ denote the inside diameters of the inner and outer tubes, 


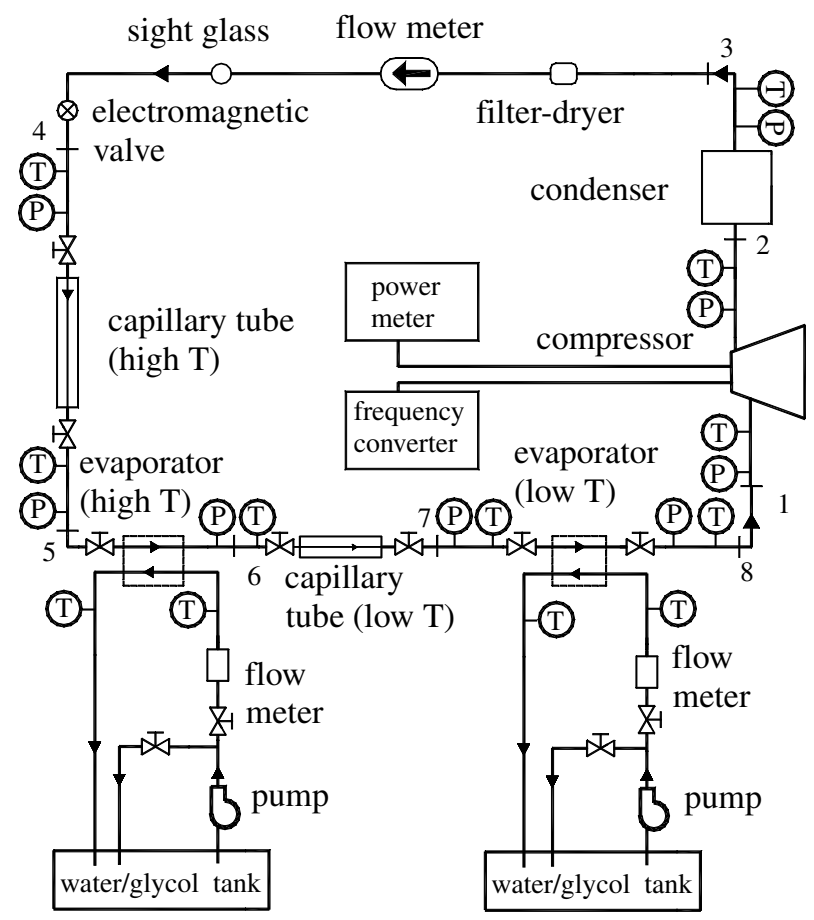

Fig. 1. Schematic diagram of the experimental facility.

Table 1

Test conditions

\begin{tabular}{|c|c|c|c|c|c|c|c|c|c|}
\hline \multicolumn{5}{|l|}{$P_{\mathrm{c}}(\mathrm{kPa})$} & \multicolumn{5}{|l|}{$f(\mathrm{~Hz})$} \\
\hline 1764 & 1666 & 1568 & 1470 & 1372 & 40 & 50 & 60 & 70 & 80 \\
\hline$d_{\mathrm{H}}(\mathrm{mm})$ & $d_{\mathrm{L}}(\mathrm{mm})$ & $L_{\mathrm{e}}(\mathrm{m})$ & $D_{\mathrm{i}, \mathrm{i}}(\mathrm{mm})$ & $D_{\mathrm{o}, \mathrm{i}}(\mathrm{mm})$ & $D_{\mathrm{i}, \mathrm{o}}(\mathrm{mm})$ & $D_{\mathrm{o}, \mathrm{o}}(\mathrm{mm})$ & & & \\
\hline 1.0 & 1.4 & 2 & 8.7 & 9.525 & 14.85 & 15.875 & & & \\
\hline$L_{\mathrm{H}}(\mathrm{m})$ & & & & & $L_{\mathrm{L}}(\mathrm{m})$ & & & & \\
\hline 1.6 & 1.9 & 2.2 & 2.5 & 2.8 & 0.3 & 0.6 & 0.9 & 1.2 & \\
\hline
\end{tabular}

respectively, while $D_{\mathrm{o}, \mathrm{i}}$ and $D_{\mathrm{o}, \mathrm{o}}$ denote the outside diameters of the inner and outer tubes, respectively. The refrigerant flows in one direction through the inner tube while the heating medium flows in the opposite direction through the annular space between the inner and outer tubes. The heating media of both evaporators is a water/glycol (50/50 wt.\%) mixture to avoid icing in the annular space. Notably, the low-temperature capillary tube is shorter than the high-temperature counterpart, as the refrigerant within the low-temperature capillary tube is all two-phase, while part of the refrigerant within the high-temperature capillary tube is liquid. 
Both the heat-exchange loops are composed of a refrigerator, pump, flow meter, thermometer controller, and electrically heated unit. Depending on the operating conditions, the temperature of water/glycol entering the high- and low-temperature evaporators is set at around $25^{\circ} \mathrm{C}$ and $-9.5^{\circ} \mathrm{C}$, respectively.

The experimental variables include the condensing pressure $\left(P_{\mathrm{c}}\right)$, lengths of the capillary tubes for the high- and low-temperature evaporator $\left(L_{\mathrm{H}}\right.$ and $\left.L_{\mathrm{L}}\right)$, and compressor frequency $(f)$. The details of the test conditions are listed in Table 1 .

\section{Experimental results and analysis}

\subsection{Pressure-enthalpy diagram of the system}

Fig. 2 shows the pressure-enthalpy diagram of the system. The properties of refrigerant are obtained using REFPROP designed by McLinden et al. [20]. The encircled numbers indicate the corresponding locations as shown in Fig. 1. States 1, 2, 3, 4, and 8, are determined based on the measured pressures and temperatures. The enthalpy of state $5\left(h_{5}\right)$ equals that of state $4\left(h_{4}\right)$, since the high-temperature capillary tube is insulated. State 5 thus is determined based on $h_{5}$ and the measured $P_{5}$.

Determining state 6 requires the following equations for heat transfer:

$$
\begin{aligned}
& Q_{\mathrm{r}}=\dot{m}_{\mathrm{r}} \cdot\left(h_{\mathrm{r}, \text { out }}-h_{\mathrm{r}, \text { in }}\right) \\
& Q_{\mathrm{hm}}=\dot{m}_{\mathrm{hm}} \cdot c_{p_{\mathrm{hm}}} \cdot\left(T_{\mathrm{hm}, \text { in }}-T_{\mathrm{hm}, \text { out }}\right)
\end{aligned}
$$

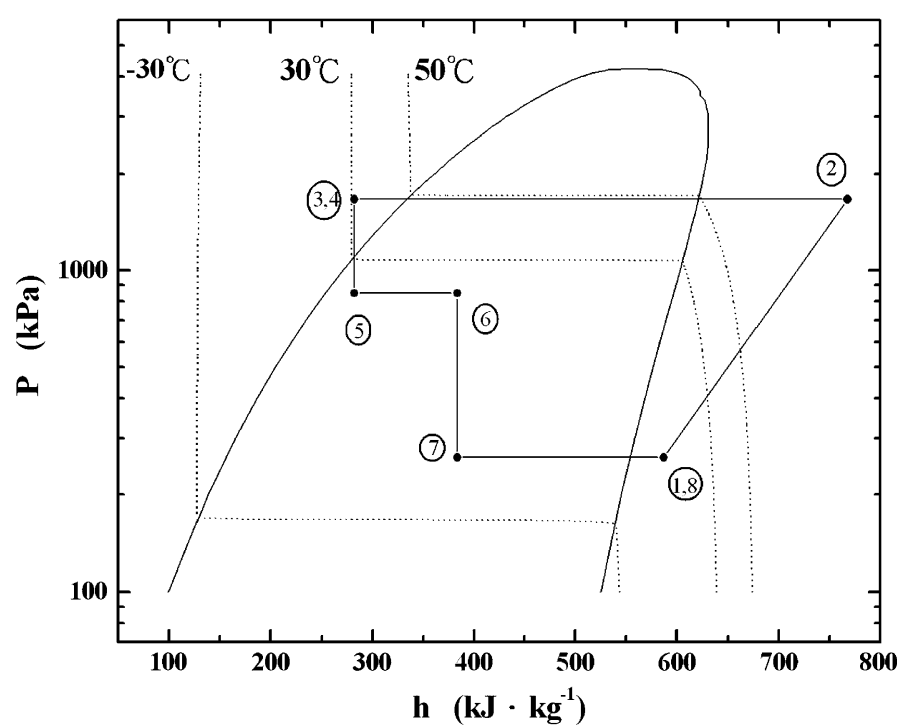

Fig. 2. A $P-h$ diagram of the refrigerant within the system $\left(P_{\mathrm{c}}=1666 \mathrm{kPa}, L_{\mathrm{H}}=2.5 \mathrm{~m}, d_{\mathrm{H}}=1.0 \mathrm{~mm}, L_{\mathrm{L}}=0.3 \mathrm{~m}\right.$, $\left.d_{\mathrm{L}}=1.4 \mathrm{~mm}, f=60 \mathrm{~Hz}\right)$. 
$Q_{\mathrm{r}}$ is assumed to be equal to $Q_{\mathrm{hm}}$ since both evaporators are insulated. For the high-temperature evaporator, $\dot{m}_{\mathrm{r}}$, water/glycol flow rate $\left(\dot{m}_{\mathrm{hm}}\right)$, and the temperatures of water/glycol entering and leaving the evaporator $\left(T_{\mathrm{hm}, \text { in }}\right.$ and $\left.T_{\mathrm{hm} \text {,out }}\right)$ are measured, while the specific heat of water/glycol $\left(C_{p_{\mathrm{hm}}}\right)$ is based on that in the literature [21]. Then, $Q_{\mathrm{hm}}$ can be obtained using Eq. (2). On the other hand, $h_{\mathrm{r} \text {,in }}$ equals $h_{5} . h_{6}$ can thus be obtained through Eq. (1). Therefore, point 6 can be fixed using the calculated $h_{6}$ and measured $P_{6}$. Since $P_{7}$ is measured and $h_{7}$ equals $h_{6}$ owing to the fact that the expansion in the capillary tube is insulated, state 7 can then be allocated. Notably, the pressure drops in heat exchangers and pipelines are neglected. To check the influence of these pressure drops on the system performance, some tests were conducted. The experimental results showed that the pressure drop across the heat exchangers and pipelines was about $10 \mathrm{kPa}$, which is relatively small compared with that across each capillary tube $(400-700 \mathrm{kPa})$.

\subsection{Refrigerant flow rate}

The analytical process used to develop the dimensionless correlations to predict $\dot{m}_{\mathrm{r}}$ in the twoevaporator refrigerating system is based on the Buckingham Pi theorem. The Buckingham Pi theorem describes the relation between a function expressed in terms of dimensional parameters and a related function expressed in terms of dimensionless parameters. The utilization of the Buckingham Pi theorem enables the important dimensionless parameters to be developed quickly and easily. The first step in this analysis is to determine the variables that may influence $\dot{m}_{\mathrm{r}}$ as follows: both the diameters and lengths of the high-temperature $\left(d_{\mathrm{H}}\right.$ and $\left.L_{\mathrm{H}}\right)$ and low-temperature capillary tube $\left(d_{\mathrm{L}}\right.$ and $\left.L_{\mathrm{L}}\right)$, the inlet conditions of refrigerant $\left(P_{\mathrm{c}}\right.$ and $\left.\Delta T_{\mathrm{sc}}\right)$, the frequency of compressor $(f)$, and the saturated properties of R-290 (liquid density $\rho_{\mathrm{f}}$, liquid viscosity $\mu_{\mathrm{f}}$, and liquid specific heat $c_{p_{\mathrm{f}}}$ ). Furthermore, $L_{\mathrm{H}}$ and $L_{\mathrm{L}}$ are non-dimensionalized by $d_{\mathrm{H}}$ and $d_{\mathrm{L}}$, respectively. However, to non-dimensionalize $\dot{m}_{\mathrm{r}}, P_{\mathrm{c}}, \Delta T_{\mathrm{sc}}$, and $f$, a new repeating variable $\bar{d}$, based on the definition of hydraulic diameter, is defined as $\left(d_{\mathrm{H}}^{2}+d_{\mathrm{L}}^{2}\right) \cdot\left(d_{\mathrm{H}}+d_{\mathrm{L}}\right)^{-1} \cdot \dot{m}_{\mathrm{r}}$ can then be expressed as

$$
\dot{m}_{\mathrm{r}}=f_{1}\left(P_{\mathrm{c}}, L_{\mathrm{H}}, L_{\mathrm{L}}, d_{\mathrm{H}}, d_{\mathrm{L}}, \bar{d}, \Delta T_{\mathrm{sc}}, \rho_{\mathrm{f}}, c_{p_{\mathrm{f}}}, \mu_{\mathrm{f}}, f\right)
$$

where $d_{\mathrm{H}}, d_{\mathrm{L}}, \bar{d}, \rho_{\mathrm{f}}, \mu_{\mathrm{f}}$, and $c_{p_{\mathrm{f}}}$ denote the repeating variables. Therefore, the dimensionless correlation for $\dot{m}_{\mathrm{r}}$ is

$$
\Pi_{8}=A \cdot \Pi_{1}^{B} \cdot \Pi_{2}^{C} \cdot \Pi_{3}^{D} \cdot \Pi_{4}^{E} \cdot \Pi_{5}^{F}
$$

$\Pi_{1}, \Pi_{2}, \Pi_{3}, \Pi_{4}$, and $\Pi_{5}$ in Eq. (4) denote the dimensionless parameters of $P_{\mathrm{c}}, L_{\mathrm{H}}, L_{\mathrm{L}}, \Delta T_{\mathrm{sc}}$, and $f$, respectively, as shown in Table 2 . The values of constant $A$ and exponents of the $\Pi$ parameters are obtained by substituting the experimental values into the statistical software STATISTICA. Table 3 lists the resultant dimensionless correlations.

The range of maximum error, $\beta$, in Table 3 represents the maximum deviation of the experimental data from the predicted values, while the coefficient of determination, $R^{2}$, is a relative comparison criterion between the experimental and predicted values. The dimensionless correlation improves as $R^{2}$ approaches 1 .

The dimensionless correlations for the dependent parameters include both the detailed and simplified forms. The simplified form is a function of the more important independent variables which are determined based on the relative values of the exponents of $\Pi$ parameters in the detailed form. Both detailed and simplified expressions of $\Pi_{8}$, Eqs. (5) and (6), are listed in Table 3. 
Table 2

Dimensionless parameters $\Pi$ group

\begin{tabular}{|c|c|c|}
\hline$\overline{\text { Pi-groups }}$ & Definition & Effect \\
\hline$\Pi_{1}$ & $\frac{\bar{d}^{2} \cdot \rho_{\mathrm{f}} \cdot P_{\mathrm{c}}}{\mu_{\mathrm{f}}^{2}}$ & Condensing pressure \\
\hline$\Pi_{2}$ & $\left(\frac{L_{\mathrm{H}}}{d_{\mathrm{H}}}\right)$ & Geometry \\
\hline$\Pi_{3}$ & $\left(\frac{L_{\mathrm{L}}}{d_{\mathrm{L}}}\right)$ & Geometry \\
\hline$\Pi_{4}$ & $\left(\frac{\bar{d}^{2} \cdot \rho_{\mathrm{f}}^{2} \cdot c_{p_{\mathrm{f}}} \cdot \Delta T_{\mathrm{sc}}}{\mu_{\mathrm{f}}^{2}}\right)$ & Subcooling \\
\hline$\Pi_{5}$ & $\frac{\bar{d}^{2} \cdot f \cdot \rho_{\mathrm{f}}}{\mu_{\mathrm{f}}}$ & Compressor frequency \\
\hline$\Pi_{6}$ & $\left(\frac{\bar{d}^{2} \cdot \rho_{\mathrm{f}}^{2} \cdot c_{p_{\mathrm{f}}} \cdot \mathrm{LMTD}_{\mathrm{H}}}{\mu_{\mathrm{f}}^{2}}\right)$ & $\mathrm{LMTD}_{\mathrm{H}}$ \\
\hline$\Pi_{7}$ & $\left(\frac{\bar{d}^{2} \cdot \rho_{\mathrm{f}}^{2} \cdot c_{p_{\mathrm{f}}} \cdot \mathrm{LMTD}_{\mathrm{L}}}{\mu_{\mathrm{f}}^{2}}\right)$ & LMTD $_{\mathrm{L}}$ \\
\hline$\Pi_{8}$ & $\frac{\dot{m}_{\mathrm{r}}}{\overline{\bar{d} \cdot \mu_{\mathrm{f}}}}$ & Mass flow rate \\
\hline$\Pi_{9}$ & $\overline{c_{p_{\mathrm{f}}} \cdot \mu_{\mathrm{f}}}$ & $\mathrm{hc}_{\mathrm{H}}$ \\
\hline$\Pi_{10}$ & $\frac{\mathrm{hc}_{\mathrm{L}} \cdot \bar{d}}{c_{p_{\mathrm{f}}} \cdot \mu_{\mathrm{f}}}$ & $\mathrm{hc}_{\mathrm{L}}$ \\
\hline $\begin{array}{l}\Pi_{11} \\
\Pi_{12}\end{array}$ & $\frac{Q_{\mathrm{H}}}{Q_{\mathrm{H}}+Q_{\mathrm{L}}}$ & $\begin{array}{l}\text { Ratio of } Q_{\mathrm{H}} \\
\text { Quality }\end{array}$ \\
\hline
\end{tabular}

Table 3

Dimensionless correlations of $\dot{m}_{\mathrm{r}}, \mathrm{hc}_{\mathrm{H}}, \mathrm{hc}_{\mathrm{L}}$, and $\alpha: \Pi_{n}=A \cdot \Pi_{1}^{B} \cdot \Pi_{2}^{C} \cdot \Pi_{3}^{D} \cdot \Pi_{4}^{E} \cdot \Pi_{5}^{F} \cdot \Pi_{6}^{G} \cdot \Pi_{7}^{H}$

\begin{tabular}{llllllllllll}
\hline & $A$ & $B$ & $C$ & $D$ & $E$ & $F$ & $G$ & $H$ & $R^{2}$ & $\beta(\%)$ & Eq. \\
\hline$\Pi_{8, a}$ & $10^{-1.438}$ & 0.411 & -0.425 & -0.055 & 0.2246 & 0.0243 & - & - & 0.9903 & -4 to +5 & $(5)$ \\
$\Pi_{8, b}$ & $10^{-1.678}$ & 0.492 & -0.426 & - & 0.164 & - & - & - & 0.9521 & -10 to +8 & $(6)$ \\
$\Pi_{9, a}$ & $10^{-4.52}$ & -0.343 & 0.097 & -0.209 & -0.045 & -0.021 & 0.888 & - & 0.97412 & -16 to +16 & $(11)$ \\
$\Pi_{9, b}$ & $10^{-5.535}$ & -0.389 & - & -0.165 & - & - & 0.987 & - & 0.97181 & -16 to +18 & $(12)$ \\
$\Pi_{10, a}$ & $10^{-6.095}$ & -0.038 & -0.185 & -0.08 & 0.023 & 0.00002 & - & 0.688 & 0.91753 & -12 to +16 & $(14)$ \\
$\Pi_{10, b}$ & $10^{-6.451}$ & - & -0.185 & - & - & - & - & 0.689 & 0.83736 & -16 to +23 & $(15)$ \\
$\Pi_{11, a}$ & $10^{-1.416}$ & -0.253 & 0.0815 & 0.020 & -0.052 & -0.027 & 1.563 & -0.999 & 0.98818 & -10 to +10 & $(17)$ \\
$\Pi_{11, b}$ & $10^{-0.95}$ & -0.324 & - & - & - & - & 1.544 & -0.986 & 0.98611 & -10 to +10 & $(18)$ \\
\hline
\end{tabular}

Moreover, $R^{2}$ of the simplified form of $\Pi_{8}$, Eq. (6), is 0.9521 , which is comparable to that of the detailed form, 0.9903 . Therefore, Eq. (6) cannot only simplify the calculating process but also result in acceptable prediction.

Eq. (5) in Table 3 shows that $\dot{m}_{\mathrm{r}}$ is affected primarily by $P_{\mathrm{c}}, L_{\mathrm{H}}$, and $\Delta T_{\mathrm{sc}}$. Notably, $\dot{m}_{\mathrm{r}}$ increases with $P_{\mathrm{c}}$ and $\Delta T_{\mathrm{sc}}$, but decreases with $L_{\mathrm{H}}$. Since increasing $\Delta T_{\mathrm{sc}}$ increases the proportion of the refrigerant in the liquid state in the capillary tube, $\dot{m}_{\mathrm{r}}$ increases with $\Delta T_{\mathrm{sc}}$. Notably, the effect 


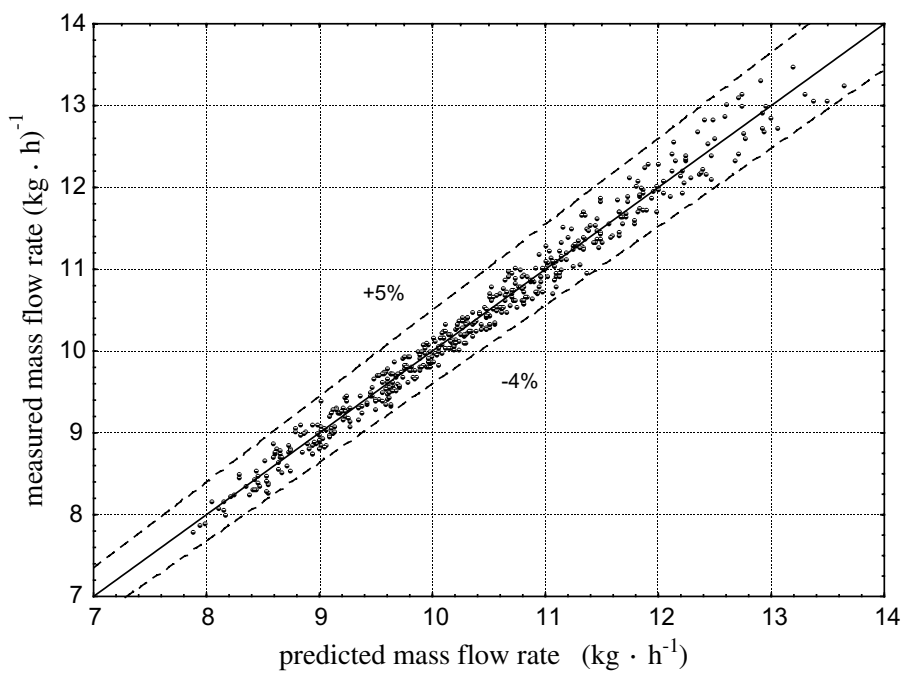

Fig. 3. Measured $\dot{m}_{\mathrm{r}}$ versus predicted $\dot{m}_{\mathrm{r}}$ using Eq. (5).

of $P_{\mathrm{c}}$ on $\dot{m}_{\mathrm{r}}$ is more significant than that of $\Delta T_{\mathrm{sc}}$. Fig. 3 shows that $\beta$ for $\dot{m}_{\mathrm{r}}$ using Eq. (5) is between $-4 \%$ and $+5 \%$, which agrees with the experimental data.

\subsection{Heat transfer coefficient of refrigerant}

The heat transfer coefficient of refrigerant $\left(\mathrm{hc}_{\mathrm{r}}\right)$ directly affects the performance of the evaporator, and thus a study of the heat transfer coefficient of refrigerant is essential. In the experiment, the quality of refrigerant in the high- and low-temperature evaporators is different, and the analysis for $\mathrm{hc}_{\mathrm{r}}$ thus is divided into two categories $\left(\mathrm{hc}_{\mathrm{H}}\right.$ and $\mathrm{hc} \mathrm{c}_{\mathrm{L}}$ ).

For a given evaporator, the cooling capacity $(Q)$ may be expressed as

$$
Q=(U \cdot A) \cdot(\mathrm{LMTD})
$$

where the products of the overall heat transfer coefficient $(U)$ and the heat transfer area $(A)$ and the logarithmic-mean temperature difference (LMTD) are defined as

$$
\begin{aligned}
& (U \cdot A)=\left(\frac{1}{\mathrm{hc}_{\mathrm{r}} \cdot A_{\mathrm{i}}}+R+\frac{1}{\mathrm{hc}_{\mathrm{hm}} \cdot A_{\mathrm{o}}}\right)^{-1} \\
& (\mathrm{LMTD})=\frac{\left(T_{\mathrm{hm}, \text { out }}-T_{\mathrm{r}, \text { in }}\right)-\left(T_{\mathrm{hm}, \text { in }}-T_{\mathrm{r}, \text { out }}\right)}{\ln \left(\frac{\left(T_{\mathrm{hm}, \text { out }}-T_{\mathrm{r}, \text { in }}\right)}{\left(T_{\mathrm{hm}, \text { in }}-T_{\mathrm{r}, \text { out }}\right)}\right)}
\end{aligned}
$$

For both evaporators, the inside and outside heat transfer areas, $A_{\mathrm{i}}$ and $A_{\mathrm{o}}$, are fixed, while the conduction resistances $(R)$ are more or less constant. Keeping $\dot{m}_{\mathrm{hm}}$ constant and assuming negligible variations of $T_{\mathrm{hm} \text {,in }}$, the heat transfer coefficients of the heating media $\left(\mathrm{hc}_{\mathrm{hm}}\right)$ are more or less fixed. With all temperatures in Eq. (9) measured, the experimental values of $\mathrm{hc}_{\mathrm{H}}$ and hc $\mathrm{L}$ can be obtained through Eqs. (2), (7), (8) and (9). 
For the two-phase flow in the evaporator, the heat transfer involves both nucleate boiling and forced-convection. Since nucleate boiling heat transfer increases with LMTD [22] while forcedconvection heat transfer increases with Reynolds number, which is proportional to $\dot{m}_{\mathrm{r}}$, the dimensionless parameter of $\mathrm{hc}_{\mathrm{H}}$ is represented by $\Pi_{9}$ as follows:

$$
\Pi_{9}=A \cdot \Pi_{1}^{B} \cdot \Pi_{2}^{C} \cdot \Pi_{3}^{D} \cdot \Pi_{4}^{E} \cdot \Pi_{5}^{F} \cdot \Pi_{6}^{G}
$$

The dimensionless parameter of $\mathrm{LMTD}_{\mathrm{H}}$ is represented by $\Pi_{6}$, as listed in Table 2 . Moreover, Table 3 lists both detailed and simplified expressions of $\Pi_{9}$, Eqs. (11) and (12).

The exponents of $\Pi$ parameters in Eq. (11) show that hc $\mathrm{c}_{\mathrm{H}}$ is affected primarily by $P_{\mathrm{c}}, L_{\mathrm{L}}$, and $\mathrm{LMTD}_{\mathrm{H}}$. The effect of $P_{\mathrm{c}}$ on $\mathrm{hc}_{\mathrm{H}}$ is more significant than that of $L_{\mathrm{L}}$. Increasing $P_{\mathrm{c}}$ increases $\dot{m}_{\mathrm{r}}$, and the pressure of the high-temperature evaporator, which in turn increases $T_{\text {r, in }}$ in Eq. (9) since the refrigerant in the high-temperature evaporator is two-phase. Consequently LMTD $_{\mathrm{H}}$ decreases with $P_{\mathrm{c}}$. The effect of $\mathrm{LMTD}_{\mathrm{H}}$ induced by $P_{\mathrm{c}}$ seems to dominate that of $\dot{m}_{\mathrm{r}}$. Therefore, hc $\mathrm{c}_{\mathrm{H}}$ decreases with $P_{\mathrm{c}}$. Additionally, both $\dot{m}_{\mathrm{r}}$ and $\mathrm{LMTD}_{\mathrm{H}}$ decreases with $L_{\mathrm{L}}$ [4], which induce hc $\mathrm{H}_{\mathrm{H}}$ to decrease with $L_{\mathrm{L}}$. Intuitively, $L_{\mathrm{H}}$ is a main influence on $\mathrm{hc}_{\mathrm{H}}$. However, the pressure of the high-temperature evaporator will decrease slightly with $L_{\mathrm{H}}$ [4]. Accordingly, $\mathrm{LMTD}_{\mathrm{H}}$ increases slightly with $L_{\mathrm{H}}$. On the other hand, $\dot{m}_{\mathrm{r}}$ decreases with $L_{\mathrm{H}}$. Apparently, the effects of $\mathrm{LMTD}_{\mathrm{H}}$ and $\dot{m}_{\mathrm{r}}$ induced by $L_{\mathrm{H}}$ offset each other. $\mathrm{hc}_{\mathrm{H}}$ therefore is not noticeably affected by $L_{\mathrm{H}}$.

$R^{2}$ of Eq. (12) is 0.97181 , which is nearly the same as that of Eq. (11), 0.97412. Therefore, the simplified form of $\Pi_{9}$ may also result in good prediction accuracy. Fig. 4 shows that $\beta$ for hc $\mathrm{h}_{\mathrm{H}}$ using Eq. (11) is between $-16 \%$ and $+16 \%$.

Similarly, the dimensionless parameter of $\mathrm{hc}_{\mathrm{L}}$ is expressed by $\Pi_{11}$ as

$$
\Pi_{10}=A \cdot \Pi_{1}^{B} \cdot \Pi_{2}^{C} \cdot \Pi_{3}^{D} \cdot \Pi_{4}^{E} \cdot \Pi_{5}^{F} \cdot \Pi_{7}^{H}
$$

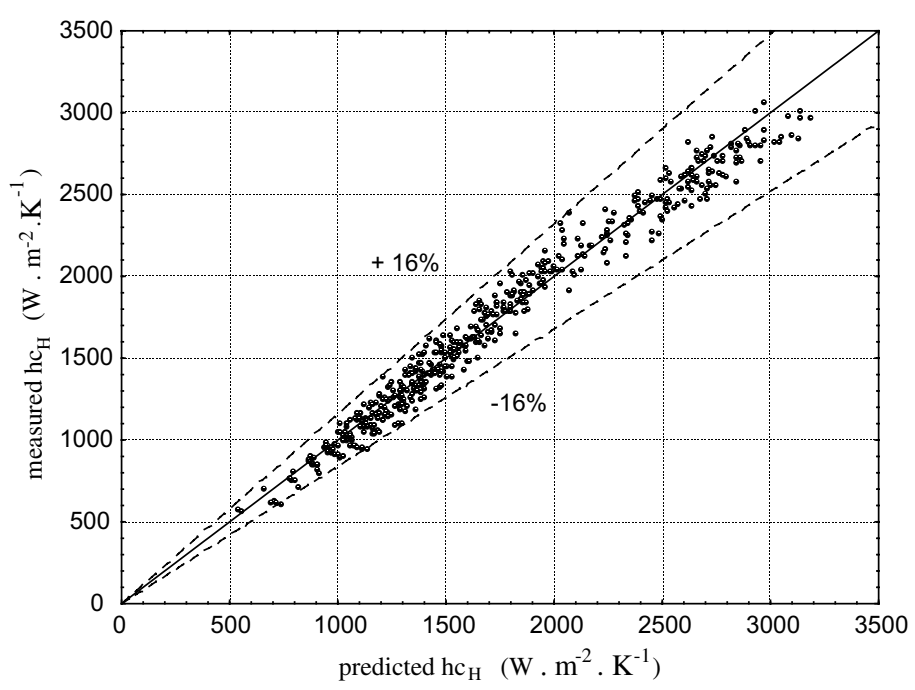

Fig. 4. Measured $h c_{H}$ versus predicted $h c_{H}$ using Eq. (11). 


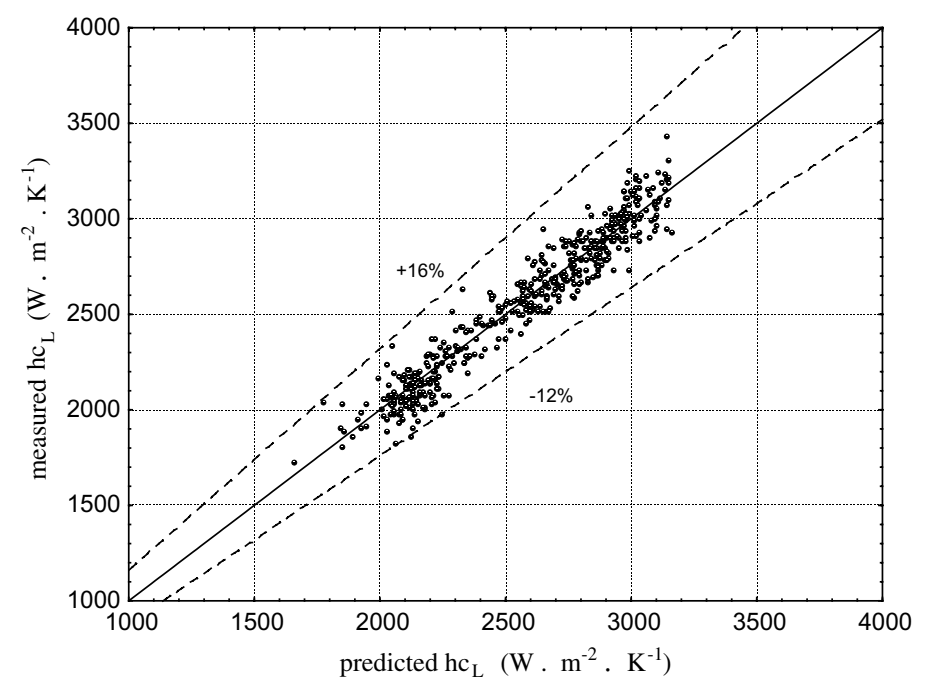

Fig. 5. Measured $h c_{L}$ versus predicted $h c_{L}$ using Eq. (14).

The dimensionless parameter of $\mathrm{LMTD}_{\mathrm{L}}$ is represented by $\Pi_{7}$ as shown in Table 2 . Table 3 also lists the detailed and simplified expressions of $\Pi_{10}$, Eqs. (14) and (15). Eq. (14) shows that $L_{\mathrm{H}}$ and $\mathrm{LMTD}_{\mathrm{L}}$ are the main factors affecting $\mathrm{hc}_{\mathrm{L}}$. $\mathrm{hc}_{\mathrm{L}}$ decreases with $L_{\mathrm{H}}$ but increases with $\mathrm{LMTD}_{\mathrm{L}}$. Meanwhile, $\dot{m}_{\mathrm{r}}$ decreases but LMTD $\mathrm{L}_{\mathrm{L}}$ increases with $L_{\mathrm{H}}$ [4]. Apparently, hc $\mathrm{L}_{\mathrm{L}}$ decreases with $L_{\mathrm{H}}$ since the effect of $\dot{m}_{\mathrm{r}}$ on $\mathrm{hc}_{\mathrm{L}}$ dominates that of $\mathrm{LMTD}_{\mathrm{L}}$ induced by $L_{\mathrm{H}}$. Again, intuitively $L_{\mathrm{L}}$ could be expected to have a significant effect on $\mathrm{hc}_{\mathrm{L}}$. However, both $\dot{m}_{\mathrm{r}}$ and the pressure of the low-temperature evaporator will decrease slightly with $L_{\mathrm{L}}$. Accordingly $\mathrm{LMTD}_{\mathrm{L}}$ increases slightly with $L_{\mathrm{L}}$ [4]. Apparently, the effect of $\dot{m}_{\mathrm{r}}$ on hc $\mathrm{L}$ offsets that of $\mathrm{LMTD}_{\mathrm{L}}$ when $L_{\mathrm{L}}$ is changed. Therefore, hc $\mathrm{L}_{\mathrm{L}}$ is not significantly changed by $L_{\mathrm{L}}$. Fig. 5 shows that $\beta$ for hc $\mathrm{L}_{\mathrm{L}}$ using Eq. (14) is between $-12 \%$ and $+16 \%$.

\subsection{Ratio of the cooling capacity of the high-temperature evaporator}

The relative cooling capacities of the two evaporators in the system may vary among applications. Therefore, the ratio of the cooling capacity of the high-temperature evaporator to the total capacity $(\alpha)$ is an important system characteristic. Table 2 lists the dimensionless parameter of $\alpha$, whish is defined as $\Pi_{11}$. Now $\alpha$ can be expressed as

$$
\Pi_{11}=A \cdot \Pi_{1}^{B} \cdot \Pi_{2}^{C} \cdot \Pi_{3}^{D} \cdot \Pi_{4}^{E} \cdot \Pi_{5}^{F} \cdot \Pi_{6}^{G} \cdot \Pi_{7}^{H}
$$

Table 3 lists both detailed and simplified expressions of $\Pi_{9}$, Eqs. (17) and (18). The relative values of the exponents of $\Pi$ parameters in Eq. (17) show that $\alpha$ is primarily affected by $P_{\mathrm{c}}, \mathrm{LMTD}_{\mathrm{H}}$, and $\mathrm{LMTD}_{\mathrm{L}} \cdot \alpha$ decreases with $P_{\mathrm{c}}$ and $\mathrm{LMTD}_{\mathrm{L}}$ but increases with $\mathrm{LMTD}_{\mathrm{H}}$. However, the effect of LMTD $_{\mathrm{L}}$ on $\alpha$ is more significant than that of $P_{\mathrm{c}}$. Notably, $\alpha$ does not change apparently with $L_{\mathrm{H}}$ and $L_{\mathrm{L}}$. When $L_{\mathrm{H}}$ is increased, $\dot{m}_{\mathrm{r}}$ decreases but $\Delta h_{\mathrm{H}}$ increases. Therefore, the cooling capacity of high-temperature evaporator, $Q_{\mathrm{H}}$, remains more or less the same for different $L_{\mathrm{H}}$ [4]. Additionally, with increasing $L_{\mathrm{L}}$, the variation of $Q_{\mathrm{H}}$ will offset that of $Q_{\mathrm{L}}$. Therefore, $\alpha$ is not noticeably affected by $L_{\mathrm{L}}$. 


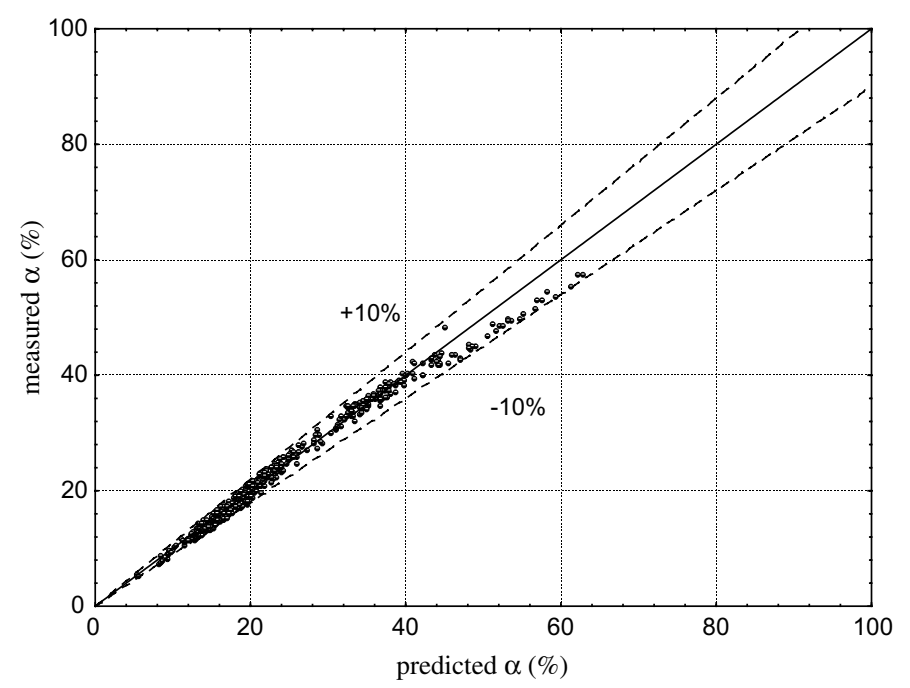

Fig. 6. Measured $\alpha$ versus predicted $\alpha$ using Eq. (17).

$R^{2}$ of the simplified form of $\Pi_{11}$ is 0.98611 , which is comparable to that of the detailed form, 0.98818. Therefore, a reasonable prediction may be given by Eq. (18). Fig. 6 shows that $\beta$ for $\alpha$ using Eq. (17) is between $-10 \%$ and $+10 \%$. The predictions are within the acceptable range from the viewpoint of heat transfer.

\subsection{Correlations from literatures}

For the mass flow rate of the fluid flowing through an adiabatic capillary tube, Bittle et al. [12] developed a series of dimensionless correlations for $\dot{m}_{\mathrm{r}}$. For the subcooled inlet condition, the correlation for $\dot{m}_{\mathrm{r}}$ is [12]

$$
\Pi_{8, \mathrm{c}}=0.0055 \cdot \Pi_{1}^{0.5485} \cdot \Pi_{2}^{-0.3668} \cdot \Pi_{4}^{0.1624}
$$

Fig. 7 shows the comparison of $\dot{m}_{\mathrm{r}}$ calculated by Eq. (19) with the present experimental measurements, in which $d_{\mathrm{H}}$ is used instead of $\bar{d}$. Notably, the form of $\Pi_{8, c}$ is the same as that of $\Pi_{8, b}$, but some differences exist between the exponents of $\Pi$ parameters.

For the two-phase inlet condition, the correlation is [12]

$$
\Pi_{8, d}=1.31 \times 10^{-4} \cdot \Pi_{1}^{0.8326} \cdot \Pi_{3}^{-0.2867} \cdot \Pi_{12}^{1.1013}
$$

where $\Pi_{12}=(1-x)$ represents the two-phase state of the entering refrigerant. Notably, the difference between Eqs. (20) and (19) is the inlet state of the refrigerant. Fig. 7 shows the comparison of $\dot{m}_{\mathrm{r}}$ calculated by Eq. (20) with the present experimental measurements, in which $P_{6}$ and $d_{\mathrm{L}}$ is used instead of $P_{\mathrm{c}}$ and $\bar{d}$, respectively. The analytical results show that $\beta$ for $\dot{m}_{\mathrm{r}}$ from Eq. (19) is reasonable while that from Eq. (20) is not so good.

Notably, the correlations, Eqs. (19) and (20), can only predict $\dot{m}_{\mathrm{r}}$ through one capillary tube. Table 4 lists $\beta$ induced by Eqs. (19) and (20). The analytical results show that the error range 


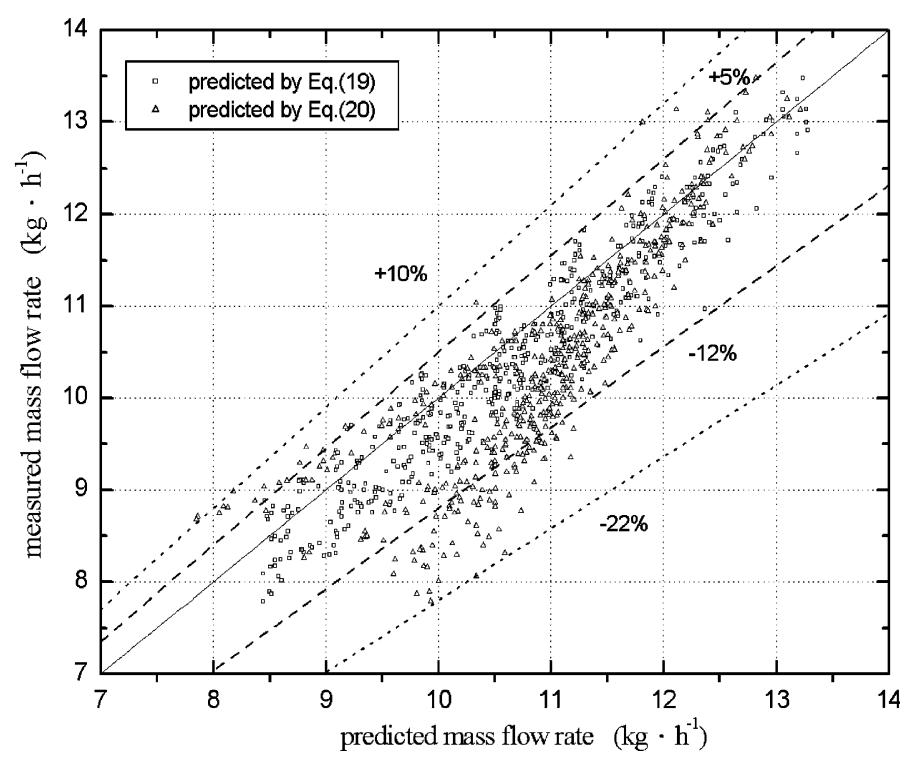

Fig. 7. Measured $\dot{m}_{\mathrm{r}}$ versus correlations from literature [12].

Table 4

$\beta$ of $\dot{m}_{\mathrm{r}}, \mathrm{hc}_{\mathrm{H}}$, and $\mathrm{hc}_{\mathrm{L}}$ calculated by correlations with experimental data proposed by the paper

\begin{tabular}{llll}
\hline & $\beta$ of $\dot{m}_{\mathrm{r}}, \%$ & $\beta$ of hc $\mathrm{hc}_{\mathrm{H}}, \%$ & $\beta$ of hc $_{\mathrm{L}}, \%$ \\
\hline Inlet subcooled [12] & -12 to +5 & - & - \\
Inlet two-phase [12] & -22 to +10 & - & - \\
Gungor-Winterton [15] & - & -40 to -8 & -31 to +2 \\
Kandlikar [16] & - & 0 to +45 & -10 to +50 \\
Steiner-Taborek [17] & - & -7 to +10 & -12 to +8 \\
Wattelet et al. [18] & - & -10 to +9 & -11 to +9 \\
\hline
\end{tabular}

between the measured and calculated results using the correlations, Eqs. (19) and (20), are wider than that using the correlation, Eq. (5).

For the two-phase heat transfer coefficients in evaporators, $\mathrm{hc}_{\mathrm{H}}$ and $\mathrm{hc} \mathrm{L}_{\mathrm{L}}$, some correlations may be identified from various sources, such as [15-18]. Unfortunately these correlations are quite complex. Therefore, no details are listed here. However, $\mathrm{hc}_{\mathrm{H}}$ and $\mathrm{hc}_{\mathrm{L}}$ calculated by the correlations from [15-18] are compared with the experimental measurements of $\mathrm{hc}_{\mathrm{H}}$ and $\mathrm{hc}_{\mathrm{L}}$.

Table 4 lists the entire error range between the measured and calculated results using the correlations from [15-18]. The analytical results show that both $\mathrm{hc}_{\mathrm{H}}$ and $\mathrm{hc}_{\mathrm{L}}$ by the correlation from [15] are over-predicted by about $0-40 \%$, while those by the correlation from [16] are under-predicted by about $0-35 \%$. Notably, $\beta$ for $\mathrm{hc}_{\mathrm{H}}$ and $\mathrm{hc}_{\mathrm{L}}$ from the correlations of $[17,18]$ is smaller than those from the correlations, Eqs. (11) and (14). However, the required variables of the correlations found here are much fewer than those of the correlations from $[17,18]$. 


\section{Conclusions}

This study develops the dimensionless correlations for analyzing the characteristics of the series-connected two-evaporator refrigerating system with R-290 as the refrigerant. Some conclusions may be drawn as follows:

1. The dimensionless correlations for $\dot{m}_{\mathrm{r}}, \mathrm{hc}_{\mathrm{H}}, \mathrm{hc}_{\mathrm{L}}$, and $\alpha$ are developed based on the experimental results and Buckingham Pi theorem. Compared with the experimental results, the accuracy of the dimensionless correlations for $\dot{m}_{\mathrm{r}}$ is quite good, while that for $\mathrm{hc}_{\mathrm{H}}, \mathrm{hc}_{\mathrm{L}}$, and $\alpha$ is acceptable.

2. $\dot{m}_{\mathrm{r}}$ is primarily affected by $P_{\mathrm{c}}, L_{\mathrm{H}}$, and $\Delta T_{\mathrm{sc}}$. The dominant factors for hc $\mathrm{c}_{\mathrm{H}}$ are $P_{\mathrm{c}}, L_{\mathrm{L}}$, and $\mathrm{LMTD}_{\mathrm{H}}$, while those for $\mathrm{hc}_{\mathrm{L}}$ are $L_{\mathrm{H}}$ and $\mathrm{LMTD}_{\mathrm{L}}$. As for $\alpha$ the dominant factors are $P_{\mathrm{c}}$, $\mathrm{LMTD}_{\mathrm{H}}$, and $\mathrm{LMTD}_{\mathrm{L}}$.

3. The frequency of the compressor is not a main influence on $\dot{m}_{\mathrm{r}}, \mathrm{hc}_{\mathrm{H}}, \mathrm{hc}_{\mathrm{L}}$, and $\alpha$.

4. The accuracy predicted by some correlations from literatures is good. However, the specific correlations are much more complicated than those presented here.

5. The dimensionless correlations in this study may be applied to the design of a two-evaporator refrigerating system. However, the superheating degree of refrigerant may be considered a variable for further work. Moreover, the properties of other environment-friendly refrigerants are worthy of further investigation. Additionally, the dimensionless correlations for R290 may be applied to other refrigerants with refrigerating properties close to R-290, such as $\mathrm{R}-22$.

\section{Acknowledgment}

The authors would like to acknowledge the financial support by the National Science Council of Taiwan under the contract of NSC89-2212-E-002-143.

\section{References}

[1] A. Lorenz, K. Meutzner, On application of nonazeotropic two-component refrigerants in domestic refrigerators and home freezers, in: Proc. of the XIV Int. Cong. Refrig., Moscow, vol. IIR, Paris, 1975.

[2] K.E. Simmons, K. Kim, R. Radermacher, Experimental study of independent temperature control of refrigerator compartments in a modified Lorenz-Meutzner cycle, ASME 34 (1995) 67-73.

[3] K.E. Simmons, I. Haider, R. Radermacher, Independent compartment temperature control of LorenzMeutznerand and modified Lorenz-Meutzner cycle refrigerators, ASHRAE Trans. 102 (1) (1996) 1085-1092.

[4] C.J. Li, C.C. Su, Experimental study of a series-connected two-evaporator refrigerating system with propane (R-290) as the refrigerant, Appl. Thermal Eng. 23 (2003) 1503-1514.

[5] R.Y. Li, S. Lin, Z.Y. Chen, Z.H. Chen, Metastable flow of R-12 through capillary tubes, Int. J. Refrig. 13 (1990) 181-186.

[6] S.J. Kuehl, V.W. Goldschmidt, Steady flows of R-22 through capillary tubes: Test data, ASHRAE Trans. 96 (1) (1990) 719-728.

[7] H. Wijaya, Adiabatic capillary tube Test data for HFC-134a, Int. Refrig. Conf. 5 (1992) 63-71. 
[8] P.K. Bansal, A.S. Rupasinghe, An homogeneous model for adiabatic capillary tubes, Appl. Therm. Eng. 18 (1998) 207-219.

[9] S. Wongwises, P. Chan, Two-phase separated flow model of refrigerants flowing through capillary tubes, Int. Comm. Heat Transfer 27 (3) (2000) 343-356.

[10] O. Garcia-Valladares, C.D. Perez-Segarra, A. Oliva, Numerical simulation of capillary tube expansion devices behavior with pure and mixed refrigerants considering metastable region. Part I: mathematical formulation and numerical model, Appl. Therm. Eng. 22 (2002) 173-182.

[11] O. Garcia-Valladares, C.D. Perez-Segarra, A. Oliva, Numerical simulation of capillary tube expansion devices behavior with pure and mixed refrigerants considering metastable region. Part II: experimental validation and parametric studies, Appl. Therm. Eng. 22 (2002) 379-391.

[12] R.R. Bittle, D.A. Wolf, M.B. Pate, A generalized performance prediction method for adiabatic capillary tubes, HVAC\&R Res. 4 (1) (1998) 27-43.

[13] C. Melo, R.T.S. Ferreira, C.N. Boabaid, J.M. Goncalves, M.M. Mezavila, An experimental analysis of adiabatic capillary tube, Appl. Therm. Eng. 19 (1999) 669-684.

[14] S.G. Kim, M.S. Kim, S.T. Ro, Experimental investigation of the performance of R22, R407C and R410A in several capillary tubes for air-conditioners, Int. J. Refrig. 25 (2002) 521-531.

[15] K.E. Gungor, R.H.S. Winterton, A general correlation for flow boiling in tubes and annuli, Int. J. Mass Transfer 29 (3) (1986) 351-358.

[16] S.G. Kandlikar, A general correlation for saturated two-phase flow boiling heat transfer inside horizontal and vertical tubes, ASME J. Heat Transfer 112 (1990) 219-228.

[17] D. Steiner, N. Taborek, Flow boiling heat transfer in vertical tubes correlated by an asymptotic model, Heat Transfer Eng. 13 (1992) 43-69.

[18] J.P. Wattelet, J.C. Chato, A.L. Souza, B.R. Christoffersen, Evaporative characteristics of R-12, R-134a, and a mixture at low mass fluxes, ASHRAE Trans. 100 (2) (1994) 603-615.

[19] United Nations Environment Program, Decisions of the fourth meeting of the parties to the Montreal Protocol on substances that deplete the ozone layer, Copenhagen, Denmark, 1992.

[20] M.O. McLinden, E.W. Lemmon, S.A. Klein, A.P. Peskin, NIST Thermodynamic Properties of Refrigerants and Refrigerant Mixtures Database (REFPROP), Version 6.0, National Institute of Standards and Technology, Gaithersburg, MD, 1998.

[21] ASHRAE handbook, Fundamentals (SI edition), ASHARE handbook. Fundamentals, 20.1-20.13, 1997.

[22] H.K. Forster, N. Zuber, Dynamics of vapor bubbles and boiling heat transfer, AIChE J. 1 (1955) 531-535. 